\title{
Noncontingent partial reinforcement of running: A replication'
}

\author{
MILTON A. TRAPOLD AND DAVID HOLDEN
}

UNIVERSITY OF MINNESOTA

A previous study showed, contrary to frustration theory, that the resistance to extinction( $R$ to $E$ ) of a runway response was not increased by a combination of partially reinforced direct goalbox placements (DPs) and interspersed continuously reinforced running trials, when the DPs were conducted so as to minimize locomotion. When $S$ s were required to locomote a short distance on DPs, however, partial reinforcement via $D P$, whether interspersed with reinforced running trials or not, led to increased $R$ to $E$. The present study replicated the critical groups of the earlier study with more appropriate control groups and with a larger reward magnitude. The results were in substantial agreement with the earlier ones.

In a previous experiment (Trapold \& Doren, 1965) a test was made of a prediction from frustration theory (Amsel, 1958) regarding the effect of noncontingent partial reinforcement $\left(\mathrm{pS}^{R}\right)$ upon the resistance to extinction ( $R$ to $E$ ) of a continuously reinforced response. In particular, it was expected that the $\mathrm{R}$ to $\mathbf{E}$ of a runway response, previously learned under continuous reinforcement, $\left(\mathrm{CS}^{\mathrm{R}}\right)$ would not be increased by exposing Ss to $\mathrm{pS}^{\mathrm{R}}$ direct placements (DPS) into the goalbox of the runway, but that the $R$ to $E$ of the response would be increased if these $\mathrm{pS}^{\mathrm{R}} \mathrm{DPs}$ were interspersed among further reinforced running trials. In the first case, $\mathrm{DP} \mathrm{pS}^{\mathrm{R}}$ should be sufficient to condition frustration to the cues of the goalbox, but there is no way for the running response to become conditioned to the feedback stimuli of frustration. In the second case, however, the interspersed running trials should permit running to become conditioned to the feedback stimuli of frustration, and lead to increased $\mathrm{R}$ to $\mathrm{E}$.

The results of that experiment were negative; when DP trials were administered so as to minimize locomotion, neither DP $\mathrm{pS}^{\mathrm{R}}$ by itself (P), nor $\mathrm{DP} \mathrm{pS}^{\mathrm{R}}$ interspersed with reinforced running trials $\left(\mathrm{P}_{+}\right)$produced an increase in $\mathbf{R}$ to $\mathrm{E}$. On the other hand, when DP trials were administered so that $\mathrm{Ss}$ had to locomote 8 in. to get to the foodcup, both $\mathrm{DP} \mathrm{pS}^{\mathrm{R}}$ by itself $(8 \mathrm{P})$, and $\mathrm{DP} \mathrm{pS}^{\mathrm{R}}$ interspersed with reinforced running trials (8P+) led to increased $R$ to $E$.

Trapold \& Doren (1965) took these results to indicate that $\mathrm{pS}^{\mathbf{R}}$ will not retard extinction of a response unless it is explicitly delivered following that response, and then suggested a way in which frustration theory could be modified to make it consistent with that conclusion. There was, however, one shortcoming to the Trapold \& Doren study which renders this conclusion somewhat equivocal; the control group against which all the experimental groups were compared continued to re- ceive reinforced running trials during the period that the other groups were being exposed to the novel procedures involved in DP trials and interspersed running trials. Therefore, the control group was not exposed to the same variability of trial procedures that the experimental groups were, and the failure of the $\mathrm{P}+$ condition to show increased $\mathbf{R}$ to $\mathrm{E}$ may have resulted from this use of an inappropriate control group. This failure may also have been partially the result of the relatively small magnitude of reward used in that experiment. It is known (Wagner, 1961) that the $\mathrm{pS}^{\mathbf{R}}$ effect is larger and is obtained with fewer training trials with a larger magnitude of reward. The first purpose of this study, therefore, was to replicate the P+ condition of the Trapold and Doren study with a larger reward magnitude and with a control group equated for procedural variability. A second purpose was to provide a replication of the finding that $\mathrm{pS}^{\mathrm{R}} \mathrm{DP}$ involving a short locomotion would lead to increased $R$ to $E$, even when not interspersed among reinforced running trials. This particular result was the most equivocal in the previous study, and furthermore, it too was obtained against a somewhat inappropriate control group.

\section{Method}

Ss were 40 male albino rats ca. 120 days old, and maintained at $80 \%$ of their ad lib weights.

The apparatus was a gray runway 4 in. wide, 6 in. high, and $84 \mathrm{in.}$ long. The first $12 \mathrm{in.} \mathrm{comprised} \mathrm{the}$ startbox and the last $18 \mathrm{in}$. the goalbox; both were separated from the runway proper by opaque guillotine doors. On the end wall of the goalbox was a foodcup positioned so that $S$ could not see its contents until directly over it. Running times were recorded from opening of the startdoor to the front edge of the foodcup.

After two days of adaptation to the goalbox and reinforcement pellets, all Ss were given six reinforced running trials (eight $.045 \mathrm{gm}$ pellets/trial) per day for six days. These trials were conducted as in Trapold \& Doren (1965), and had, with the exception of the first few trials, an intertrial interval ca. $45 \mathrm{~min}$. Ss were then divided into four matched (on mean running times on the last two days of acquisition) groups, each of which received a different treatment for the next eight days. Group 8P received four DP trials in the goalbox each day, one reinforced, three nonreinforced. On these trials $S$ was placed with its nose approximately 8 in. from the foodcup, and was required to locomote to the foodcup. Group $8 \mathrm{C}$ was treated exactly like group $8 \mathrm{P}$ except that all DP trials were reinforced. Group P+ also 
received four DP trials each day, one reinforced, three nonreinforced; however, these Ss were placed with their noses directly in the foodcup so that no overt locomotion was necessary. In addition, group $\mathrm{P}+$ received three reinforced running trials each day, randomly interspersed among their DP trials. Group $\mathrm{C}+$ was treated exactly as group $P_{+}$except that all their DP trials were reinforced. Ss in all groups were removed from the goalbox on DP trials as soon as they turned away from the foodcup.

Following these treatments, all Ss received six extinction trials per day for six days, conducted exactly as the initial acquisition trials except that they were never reinforced, and Ss were removed from the apparatus if they did not break the photobeam within $60 \mathrm{sec}$.

\section{Results}

The results are summarized in Fig. 1 where it is evident that (a) the two control groups extinguished at essentially equal rates, (b) group $\mathrm{P}+$ showed only a very slight increase in $R$ to $E$ over the first two days, and (c) group 8P showed a very sizable and persistent increase in $\mathbf{R}$ to $\mathrm{E}$ that was still evident at the termination of the experiment. An analysis of variance of the data depicted in Fig. 1 yielded a significant group main effect $(F=6.67, \mathrm{df}=3 / 27, \mathrm{p}<.005)$ and a significant main effect for days $(F=109.8, d f=5 / 45)$. The groups by days interaction failed to reach significance $(F=1.38$, $\mathrm{df}=15 / 135$ ). Individual contrasts on each day (using

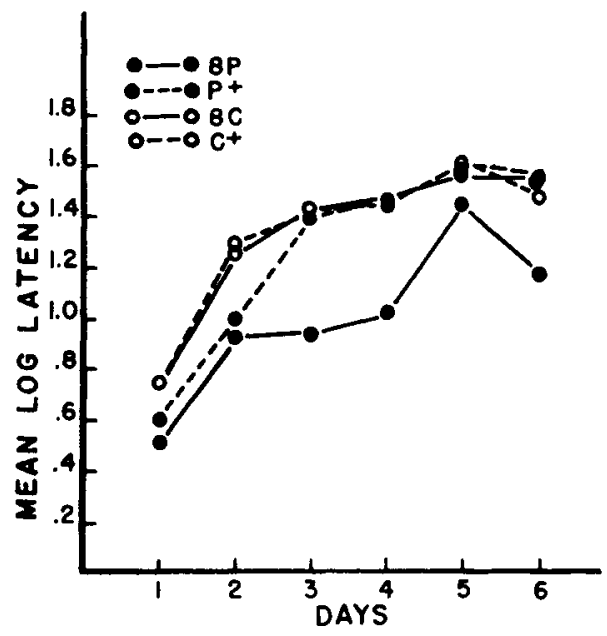

Fig. 1. Mean log latency on each day of extinction. an error estimate based upon the overall analysis) showed group $8 \mathrm{P}$ to differ from group $8 \mathrm{C}(\mathrm{p}<.05)$ on all days except the fifth, and group $\mathrm{P}+$ to differ significantly from group $\mathrm{C}+$ only on the second day. Discussion

These results are in substantial agreement with those of the previous study (Trapold \& Duren, 1965), the major difference being that there is some evidence here for a small $\mathrm{ps}^{\mathrm{R}}$ effect in group $\mathrm{P}+$. This small effect may have resulted from the larger reward magnitude used here, and further optimization of parameters may result in further increases in its magnitude. On the other hand, the effect is small enough that it could very possibly be just a random difference.

Regardless of this ambiguity, however, the present results agree with the earlier ones in showing that the opportunity to locomote on DP trials is more potent in producing increased $R$ to $E$ than are the interspersed running trials.

In the previous paper it was noted that the importance of locomotion on DP trials could be reconciled with frustration theory by assuming that the feedback stimuli of the running response itself are a very important class of stimuli to which frustration becomes conditioned. Under such an assumption, the presence of running cues in both the short run DP situation and the running trial situation provides the most important basis for generalization of frustration from the short-run DP situation to the running trial situation. The present data are quite consistent with that interpretation. The possible partial reinforcement effect in group $\mathrm{P}+$ may simply reflect the fact that frustration was also conditioned to some other stimuli common to the goalbox and runway, and that the interspersed running trials were, in fact, effective in conditioning running to the feedback of frustration.

\section{References}

Amsel, A. The role of frustrative nonreward in noncontinuous re ward situations. Psychol. Bull., 1958, 55, 102-119.

Trapold, M. A., \& Doren, D. G. The effect of noncontingent partial reinforcement on the resistance to extinction of a runway response. J. exp. Psychol., 1965, 71, 429-431.

Wagner, A. R. Effects of amount and percentage reinforcement and number of acquisition trials on conditioning and extinction. $J$. exp. Psychol., 1961, 62, 234-242.

\section{Note}

1. This research was supported in part by NIMr Grant 08799 to M.A.T. and in part by NSF Undergraduate Research Participation Program Grant GE-4079. D. H. was an undergraduate participant in this Iatter program. 